\title{
Psychophysiological effects of bathing in hot spring evaluated by EEG
}

\author{
Yasuaki Goto
}

\author{
Address: Department of Research, Japan Health \& Research Institute, Tokyo, Japan \\ from International Society on Brain and Behaviour: 3rd International Congress on Brain and Behaviour \\ Thessaloniki, Greece. 28 November - 2 December 2007 \\ Published: 17 April 2008 \\ Annals of General Psychiatry 2008, 7(Suppl I):SI 40 doi:I0.II86/I744-859X-7-SI-SI 40
}

This abstract is available from: http://www.annals-general-psychiatry.com/content/7/SI/SI 40

(c) 2008 Goto; licensee BioMed Central Ltd.

\section{Background}

Lots of Japanese have a habit to take bath with hot water over 40 degree centigrade almost every day. More than 3,000 areas of hot springs exist all over Japan and according to the survey of Japan travel bureau foundation, $90 \%$ of Japanese like to visit there as a recreation. It has been reported that bathing in hot water can augment blood flow and those kind of physical effects while taking bath have already proved by certaion number of researcheres. However psychopsysiological effects in terms of bathing in hot water have not seen yet. Yoshida et al have developed the HSK rhytms(FFR) in alpha waves measured by EEG could show the mood states. In this study, we investigate comfortableness when people take hot bath using this EEG method.

\section{Materials and methods}

EEG was performed in 22 participants (mean age $=48-$ 18) before and after 10 minutes bathing in hot spring more than 40 degree centigrade. EEG was taken at right frontal head related to calmness and at left frontal head related to relaxation. Followed by Yoshida's method, comfort score was caluclated to the range of 0 to 100 metric based on the slopes in the log power spectra of FFR.

\section{Results}

The slopes in the log power spectra of FFR calculated by EEG at FP3 increased from 0.32 to 0.46 and the one calculated by EEG at FP4 increased from 0.35 to 0,53 after bathing hot spring. "Comfort score" increased in 18 participants among 22 after bathing hot spring and average of "Comfort score" increased from 35 to 50.

\section{Conclusions}

The result suggests that bathing in hot water may contribute not only to physical effects but also psychological effects such as comfort and relief. 